\title{
Strengthening the home-to-facility continuum of newborn and child health care through mHealth: Evidence from an intervention in rural Malawi
}

\author{
Jean Christophe Fotso ${ }^{1, a}$, Lauren Bellhouse ${ }^{b}$, Linda Vesel ${ }^{a, b}$, and \\ Zachariah Jezmanc \\ ${ }^{a}$ Concern Worldwide US, New York, USA \\ b UNICEF, New York, USA \\ c VillageReach, Malawi
}

\section{Abstract}

This paper assesses the impact of a mobile health (mHealth) project on uptake of home-based care for newborn and child health, and investigates the extent to which uptake of home-based care resulted in lessened pressure on health facilities for conditions that can be handled at the household level. It uses mixed methods consisting of cross-sectional household surveys data from a quasi-experimental pre-test post-test design as well as qualitative data. The results show a large, positive effect of the project on the aggregate home-based care for child health, and a sharp, negative impact on facility-based care seeking for fever among children whose mothers/caretakers used the services offered by the intervention. Reasons for using the services mainly relate to the potential of avoiding unnecessary trips to the health facility for care that could be provided at home. The project provides insights on mHealth and community-based programming to improve newborn and child health care delivery.

Keywords: mHealth; Newborn and child health; Home-to-facility continuum of care, Malawi; sub-Saharan Africa

\section{Résumé}

Cet article analyse l'impact d'un projet de santé mobile (mSanté) sur l'utilisation des soins à domicile en santé néonatale et infantile, et examine dans quelle mesure l'utilisation des soins à domicile réduirait la pression exercée sur les établissements de santé pour les cas qui peuvent être administrés à domicile. II utilise des données quantitatives collectées à partir des enquêtes-ménages transversales basées sur une méthode quasi-expérimentale avec comparaison avant-après, et des données qualitatives. Les résultats indiquent un effet positif et net de l'intervention sur les soins à domicile pour la santé infantile, et un effet

\footnotetext{
${ }^{1}$ Corresponding author

Concern Worldwide US, 355 Lexington Avenue, 19th floor; New York NY 10017, USA.

Tel: +1-212-557-8000; Fax: +1-212-557-8004

Email: jean-christophe.fotso@concern.net
} 
négatif très prononcé sur les soins aux centres de santé pour la fièvre, parmi les enfants dont les mères/gardiennes ont utilisé les services offerts par l'intervention. Éviter les voyages non-nécessaires vers les établissements de santé lorsque les soins peuvent être administrés à domicile constitue l'une des raisons majeures de cet effet négatif. Le projet fournit une lumière concernant le domaine mSanté dans le cadre communautaire visant à améliorer la prestation des soins de santé néonatale et infantile.

Mots clés: mHealth; Newborn and child health; Home-to-facility continuum of care, Malawi; sub-Saharan Africa

\section{Introduction}

Unprecedented efforts have been made over the last two decades to reduce neonatal, infant and child deaths, and sustain progress towards the Millennium Development Goal (MDG) 4 targets (Wang et al 2014, UNICEF 2013). In sub-Saharan Africa, under-five mortality rate (U5MR) dropped from 177 deaths per 1,000 live births in 1990 to 98 deaths per I,000 live births in 2012, though a more rapid pace of decline is needed to meet the MDG target of 59 per I,000 live births (UN 20/3). In Malawi, the reduction was steeper, from 244 to 71 deaths per I,000 live births during the same period, placing the country among the few subSaharan African nations that have already met, or are on track to meet the MDG 4 goal. Malawi's infant mortality rate (IMR) also declined markedly over the 22-year period from 143 to 46 per I,000 live births (UNICEF 20I3). These infant and child mortality reductions, achieved in many low and middle-income countries, have been attributed to socioeconomic development and implementation of proven curative and preventive interventions (Wang et al. 20 I4, Black et al. 2010).

These positive mortality trends notwithstanding, the number of
Malawian infants who die before their first or fifth birthday is still unacceptably high. Another unfinished item on the infant and child health agenda is the much shallower decline in neonatal mortality rate (NMR) over the last few decades, and as a result, a consistent increase in neonatal deaths as a proportion of under five deaths (Bhutta et al. 20I4, Herbert et al 20I2, Zimba et al. 20I2). While Malawi's U5MR went down by $71 \%$ between 1990 and 2012, its NMR declined by only about a half during the same period, from 60 to 28 per I,000 live births (UNICEF 20I3). As it is now well established, the majority of neonatal deaths can be attributed to preventable causes such as pre-term birth complications, birth asphyxia and sepsis. During the post-neonatal period and childhood, the main causes of death include diarrhea, pneumonia, malaria and other infections (Black et al. 2010, de Sousa et al. 2012).

The late 1990s and early 2000s saw the realization that in countries with weak formal health systems, a homebased package of maternal and newborn health interventions could substantially reduce neonatal, infant and child mortality (Darmstadt et al. 2014, Bhutta et al. 2014, Black et al 2003). A wealth of evidence suggests that most of the 
essential newborn, infant and child care can be provided safely, effectively and at low cost at the household level (Zimba et al. 2012, ACCESS 2006). Further, community-based delivery channels with linkage to local health facilities could narrow inequities by reaching the underserved and sub-populations most in need, and improve the coverage of essential interventions (Bhutta et al. 20I4, de Sousa et al. 20I2).

The overall aim of the paper is to investigate the effects of an $\mathrm{MNCH}$ mHealth intervention in Malawi on the home-to-facility continuum of care for newborns and children. The specific objectives are to: a) assess the effect of the project on uptake of home-based care for newborn and child health; b) investigate the extent to which uptake of home-based care resulted in lessened pressure on health facilities for conditions that can be handled at the household level; and c) gain insights from caretakers of children under five years on the utility of the services offered by the intervention to support both homebased care when appropriate and referrals to facility-based care when necessary.

\section{Home-based care interventions with linkages to health facilities}

The Integrated Management of Childhood Illness (IMCl) strategy was introduced in the early 1990s by UNICEF and WHO in response to the high rates of infant and child morbidity and mortality in developing countries (CORE 2009, WHO \& UNICEF 20I2). Its greater emphasis on facility-based care remains a major constraint to access to care, given the poor economic conditions of target populations, long distance to health facilities, and cultural beliefs (Travis et al. 2004). As the model of household-to-hospital continuum of maternal, newborn and child care gained traction, especially in countries with limited availability of, and access to, facility-level care (Bahl et al 2010, ACCESS 2005, Travis et al. 2004), an extension of $\mathrm{IMCl}$ to the community, known as C-IMCl or Integrated Community Case Management (iCCM) was added (Fullerton et al. 20II, Namakhoma et al. 20/3). Through its community-level provision of care by community health workers ( $\mathrm{CHWs}$ ), iCCM is increasingly becoming a key strategy in improving newborn, infant and child health (WHO \& UNICEF 2012, de Sousa et al. 2012, Perry et al. 2014).

In Malawi, iCCM encompasses treatment for childhood pneumonia with antibiotics, treatment for diarrhea with zinc and oral rehydration salts, treatment for malaria with artemisinin combination therapy, and diagnosis of neonatal sepsis and referral with an initial antibiotic dose (Namakhoma et al. 2013). It is implemented by health surveillance assistants (HSAs) in hard-toreach areas that are beyond an $8 \mathrm{~km}$ radius from a health facility (Namakhoma et al. 2013, CORE 2009). Formerly recruited as temporary 'Smallpox Vaccinators' in the 1960's and 'Cholera Assistants' in the mid-1970s, HSAs have contributed greatly to the delivery of preventive health services in rural areas of Malawi and are credited for about $60 \%$ of vaccination coverage in rural Malawi (Kadzandira and Chilowa 200I). Over the years however, other preventive community activities have taken a larger share of HSAs' job description allowing minimal time for the management of childhood illnesses (Kok and Muula 2013). 
There is a variety of other programs implemented in Malawi that foster the home-to-facility continuum of care: promoting prevention of diseases, allowing initiation of timely treatment and referrals to the health center when needed, and addressing the communication gap of vital and relevant health information in a timely manner (Namakhoma et al. 2013). However, coverage of home-based care and compliance to referrals remains insufficient, and access to proper facility care is hampered by lack of knowledge, distance to a health facility or cost of services or transport (ACCESS 2005).

Overall, although effective community-based interventions to address maternal, newborn and child morbidity and mortality are well documented, their effective delivery remains a challenge in low-income countries (de Sousa et al. 2012, Costello et al. 2004). With the right support and knowledge, managing illnesses in the community can relieve some of the burden on already strained health facilities (Mane et al. 20I2).

\section{Potentials of $m$ Health to strengthen the continuum of home-to-facility care}

Mobile health (mHealth) is gaining momentum in public health as a tool to advance the provision and promotion of health services and practices, particularly for $\mathrm{MNCH}$ in underserved areas (Tamrat and Kachnowski 20I I, mHealth Alliance 2012). With increased availability and use of mobile phones in low-income countries, it is increasingly seen as a strategy to address barriers to accessing $\mathrm{MNCH}$ information and care (Free et al. 20l3). Major components of most $\mathrm{MNCH}$ mHealth interventions include stimulating demand and awareness for uptake of healthy behaviors through provision of information and services (Free et al 20I3, mHealth Alliance 2012).

Many mHealth interventions have been implemented in Malawi. The majority of mHealth programs focus on the health system, in particular the restocking system for drugs and the monitoring of HIV treatment (GSMA 2014). Interventions targeting patients and community members are predominantly focused on providing HIV/AIDS treatment reminders and information and promoting postnatal care visits, particularly within the context of preventing maternal to child transmission (PMTCT) of HIV (GSMA 2014). Little is known on the effectiveness of mHealth interventions for child health care in Malawi, or their potential as tools to support the management of childhood illnesses at both the community and health facility levels.

\section{Data and Methods}

\section{The Intervention}

Chipatala cha pa Foni (CCPF) - or Health Center by Phone - is an $\mathrm{MNCH}$ mHealth project which was designed to help bridge the divide between communities and life-saving health information and services by providing pregnant women and caregivers of young children with new, timely, and reliable means of accessing $\mathrm{MNCH}$ information and services. The project was implemented between July 20II and June 2013 in the predominantly rural district of Balaka, an area with some of the lowest $\mathrm{MNCH}$ indicators in Malawi. It targeted the catchment population of four health centers (Phimbi, 
Chiyendausiku, Kalembo and Mbera), covering a population of about 155,000 residents or about $45 \%$ of the district's population.

CCPF consisted of two components: a toll-free hotline offering protocolbased health information, advice and referrals, as well as a personalized mobile messaging service delivering automated tips and reminders via SMS text or voicemail to pregnant women, guardians of young children and women of childbearing age (Crawford et al. 2014). Community volunteers, trained and provided with phones, conducted community mobilization in the intervention sites and facilitated access to services to those without phones (IKI 20/3). In addition to improving $\mathrm{MNCH}$ outcomes of the target population through improved access to timely and accurate health information, the hotline was also designed to help users save on the financial cost and time of a trip to the health center for minor health issues as well as to avoid some of the problems faced by women upon arrival, such as long waiting times (IKI 20I3).

The hotline system, physically based at the district hospital, was staffed by individuals who were recruited and trained using modules from the ministry of health's curriculum for CHWs. Specifically, initial and refresher training sessions covered a wide range of issues including $\mathrm{IMCl}$, community-based $\mathrm{MNCH}$, nutrition, postnatal care, immunization, as well as hotline skills and communication, privacy and confidentiality, and data collection and management. When answering calls, hotline workers were prompted by software on touch screen devices to identify clients' symptoms and information needs. They answered the questions, offered health advice for handling minor complaints, provided information on when and where to seek care for symptoms or danger signs that could not be managed safely at home, and followed up after three to five days to check clients' adherence to the advice. The hotline system was available every day from $7 \mathrm{am}$ to $7 \mathrm{pm}$ local time (Crawford et al. 2014).

\section{Evaluation design}

The project's theory of change is depicted in Figure I. It outlines the key barriers pregnant women and caregivers of infants and children face in Malawi, including long distances to health facilities, cost of travel, and lack of timely information. It describes the intervention's major activities, and postulates that they would result in improved awareness of appropriate facility- and home-based care for mothers and children, as well as improved perception of quality of $\mathrm{MNCH}$ care. These two outcomes, in turn, will lead to improved uptake of $\mathrm{MNCH}$ services. The theory of change also draws a line of accountability beyond which changes in outcomes may not be attributed to the intervention. 


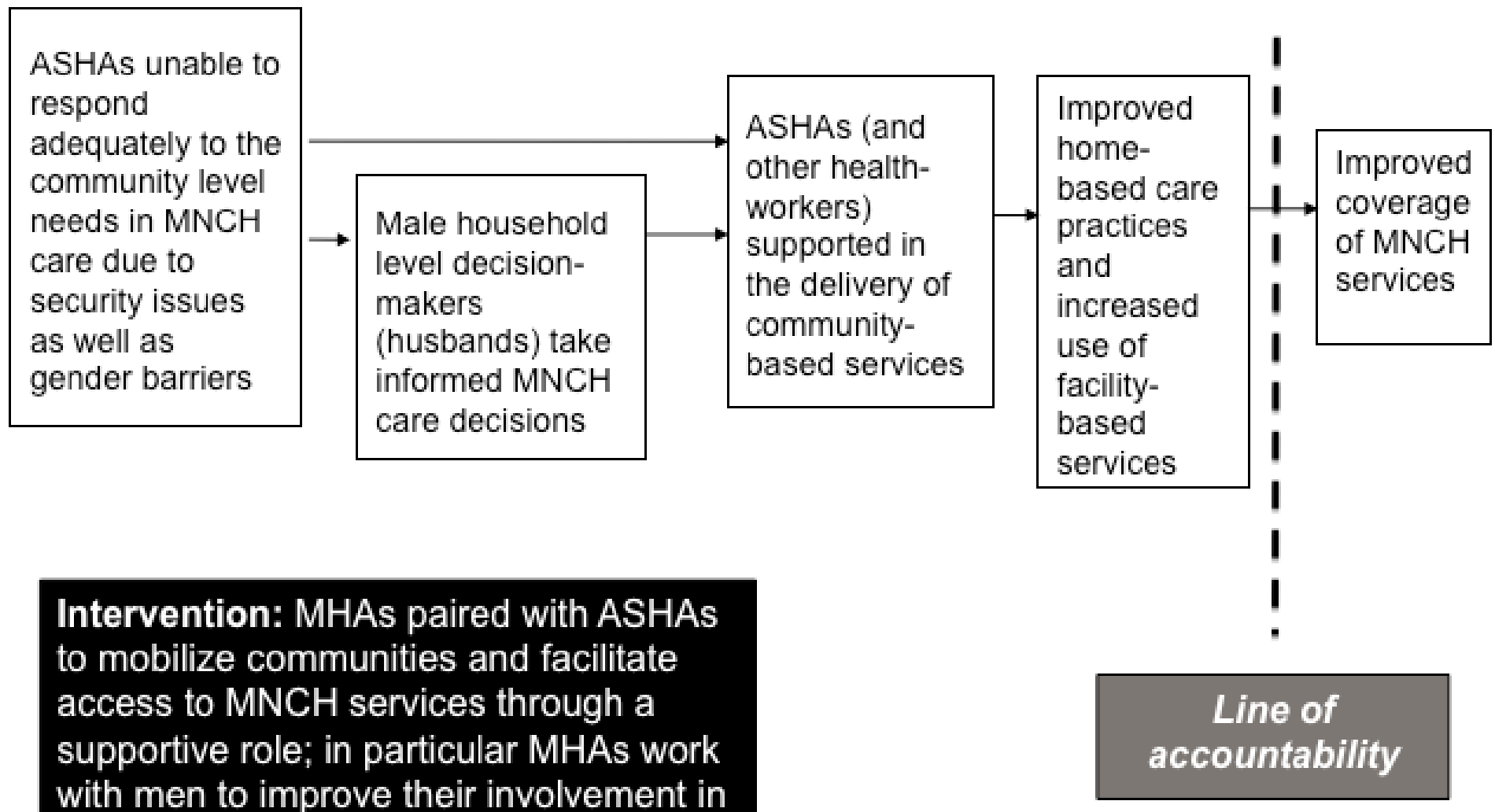

Figure I. CCPF Theory of Change 
The evaluation used a mixed methods approach. To assess the impact of the intervention on the $\mathrm{MNCH}$ outcomes of interest, the quantitative component used a two-arm quasiexperimental, pre-post design, with the neighboring Ntcheu District as the control site. Using the same eligibility criteria as for the intervention area (presence of electricity, at least two maternity nurses, and cell phone coverage), the Bwanje and Kasinje health centers were selected and their catchment areas were used as the target population for data collection for the control area (IKI 20I3). Cross-sectional household surveys were conducted at baseline (June-July 20II) and endline (April-May 2013) in both the intervention and control sites. At baseline, a Geographical Information System was used to define the catchment areas of the health facilities and to create a comprehensive list of villages. At both baseline and endline, respondents were selected using a twostage sampling procedure. First, villages, the primary sampling units, were randomly selected with equal probability. Second, households with eligible women were selected and questionnaires were administered to women of childbearing age and caregivers of under-five children (IKI 2013).

\section{Questionnaires}

Three data collection questionnaires were used at both baseline and endline, the development of which was guided by a literature review on $\mathrm{MNCH}$ in Malawi and drew largely from the Multiple Indicators Cluster Survey (MICS). The household questionnaire collected demographic data on all the members of the household as well as dwelling characteristics and household possession of durable goods. The women questionnaire collected demographic information and data on women's knowledge and utilization of maternal health services. The under-five questionnaire covered the following modules: vitamin $A$, breastfeeding, immunization, mosquito net use, and morbidity (diarrhea, acute respiratory infections and malaria/fever) - and the corresponding home-based and facilitybased care seeking behaviors. Interviewers were instructed to collect health care service seeking behavior from health passports when available to ensure a reliable measure of health seeking behavior post intervention.

\section{Variables}

The first outcome variable is the use of home-based care for child health, comprised of the following three variables:

- Exclusive breastfeeding until six months - asked for all children under the age of five years;

- Sleeping under a mosquito net the previous night - asked for all children under the age of five years;

- Receiving oral rehydration salts (ORS) when sick with diarrhea asked for children under the age of five years reported to have had diarrhea in the two weeks preceding the survey.

The three variables were aggregated using the following three-step protocol described by Kling et al. (2007). First, each indicator was recoded so that a higher value indicates a better outcome, 
as encouraged by the intervention. Second, missing values on individual variables (which ranged from $0 \%$ to $2 \%$, were imputed at the group (intervention or control) mean. Third, the aggregate values were computed as averages across the set of indicators that apply to a given respondent. For example, if a child had not had diarrhea in the last two weeks, the ORS variable will be excluded from the computation of the aggregate home-based care.

Our second outcome variable of interest is facility care for fever in the last two weeks preceding the survey, the less severe cases of which can be managed at home (WHO 20I3). Other facility-based care variables covered by the data include full vaccination by the first birthday, and visit to a health facility for symptoms of acute respiratory infections (ARI) in the previous two weeks. However, we don't expect home-based care to reduce the visits to health facilities for ARI and vaccination.

The cofactors of the use of homebased and facility-based care considered in this study include variables at the community level (mean distance to the health center), the household level (household wealth, number of children under-five, and ethnicity and religion of the household head), the woman level (ownership of a phone, education, marital status and age), and the child level (age and gender). The household wealth indicator was constructed for the overall sample from household characteristics (presence of electricity and type of drinking water, toilets, wall, roof and floor) and household possessions of durable goods (e.g. bicycle, TV, fridge, watch), using principal component analysis. The variable was recoded as a dichotomous variable using the median value as the cut-off point (low 50\%, high 50\%). While we could have used the quintiles, our interest is to categorize the population broadly as poor or non-poor. The cofactors are presented in Table I.

\section{Methods of analysis}

The impact of the intervention is quantified using the difference-indifference (DID) technique, defined for a given outcome $Y$ as:

$$
D I D(Y)=\left(\bar{Y}_{I E}-\bar{Y}_{C E}\right)-\left(\bar{Y}_{I B}-\bar{Y}_{C B}\right)
$$

where $\bar{Y}_{I E}$ and $\bar{Y}_{C E}$ represent the average outcome at endline in the intervention and control areas, respectively, and $\bar{Y}_{I B}$ and $\bar{Y}_{C B}$ represent the average outcome at baseline in the intervention and control areas, respectively. Since CCPF was offered but not compulsory, this estimate, which entails comparing the intervention and control areas without regard for the actual use of CCPF, is interpreted as an intention to treat (ITT) effect. The multivariate regression-based DID results have been shown to be largely similar to the results from the simple DID (Fotso et al. 20I5). For this reason, they are not presented in this paper. We also estimate the treatment effect on the treated (TOT) which, in contrast to the ITT, compares the individuals who actually used the services to similar individuals in the control area (Angrist et al., 1996).

\section{Qualitative data}

To gain insights into the utility of the services offered by the intervention to support both home-based care when appropriate and referrals to facility- 
based care, qualitative data analysis was also undertaken. Focus group discussions (FGDs) were conducted in each of the four intervention villages in Balaka District at endline with women users and non-users of the CCPF intervention. A trained moderator used both general and specific questions relevant to basic $\mathrm{MNCH}$ as well as the CCPF intervention to generate discussion. The FGDs were audiotaped and transcribed verbatim by an independent research team. Subsequent in-depth interviews (IDIs) were completed with a representative from each FGD, as well as a separate interview with that representative's husband. The IDI protocol consisted of a series of open-ended questions with appropriate follow-up probes that were in line with study objectives, focusing on user or non-user perspectives of the intervention as well as questions on health knowledge, care seeking, and experiences with the health system both with and without CCPF.

Transcripts were read by the coding team and lead authors searching for patterns and meanings that influence open coding (Braun and Clarke 2006). After discussing initial findings, a codebook was created with concrete definitions. All transcripts were double coded by a team of three researchers who maintained an inter-rater reliability level of above $90 \%$. An iterative process was used during the coding process, beginning with line-by-line open coding and culminating in a coding framework based on emerging themes. All decisions regarding the coding framework and emerging themes were discussed and agreed upon by all members of the coding and analysis team. Transcripts were analyzed using NVivo 10 QSR software. A grounded theory approach was taken throughout data analysis.

\section{Results}

\section{Sample description}

Table I presents the distribution of characteristics for the total sample of children under-five whose mothers/caretakers were interviewed at baseline in the intervention and control areas. It shows that the characteristics of women and children were largely similar across the intervention and control sites. The exceptions were women's access to a phone, which emerged higher in the intervention (29.9\%) compared to the control area (20.5\%), number of children under the age of five years, ethnicity, and to a lesser degree religion of the household head. As also shown in Table I, most children were aged 24 months or older and had mothers/caretakers who were married or in a union, aged 20-29, and attained a primary level education. The characteristics of the endline sample appear similar to those of the baseline sample. The number of under-five children is the only exception, with the proportion of children in households with one child increasing from about $49 \%$ in the baseline sample to $55 \%$ in the endline sample. 
Table I. Percentage distribution of children under five and their mothers/caretakers

Child characteristics

\begin{tabular}{ll} 
Baseline & \\
\hline Control Intervention & Endline
\end{tabular}

Age in months

$$
\begin{aligned}
& <12 \\
& 12-23 \\
& 24+
\end{aligned}
$$$$
25.4
$$$$
23.2
$$

19.7

22.7

Sex

$$
\text { Male }
$$

53.4

57.0

53.2

Female

48.4

51.3

51.5

51.6

48.7

48.5

Woman-level covariates

Ownership of a phone

No
Yes

79.5

70.1

71.4

20.5

29.9

28.6

Education

None

19.4

19.7

15.9

Primary

72.5

71.6

72.7

Secondary+

8. 1

8.7

I I.4

Marital status

Not in union

9.9

13.9

12.8

In union

90.1

86.1

87.2

Age in years

$$
\begin{aligned}
& <20 \\
& 20-29 \\
& 30+
\end{aligned}
$$

62.1

7.7

7.6

31.0

58.7

57.5

33.6

34.9

\section{Household level covariates}

Wealth

$$
\text { Poor (Lowest 50\%) }
$$

48.9

55.0

50.4

Rich (Highest 50\%)

51.1

45.0

49.6

Number of under- 5 chidren

$$
0
$$

5.8

53.2

$2+$

43.6

50.1

39.4

Ethnicity of the head of household

Lomwe

Ngoni

Yao

Others

Religion of the head of household

Catholic

Other Christian
5.6

75.0

6.2

13. I

15.4

67.5
20.3

18.7

37.0

24.0

16.8

37.7
15.5

37.6

28.8

18.0

16.3

47.8

http://aps.journals.ac.za 


\begin{tabular}{lccc} 
& \multicolumn{2}{c}{ Baseline } & \\
\cline { 2 - 3 } & Control & Intervention & \\
Muslim & 5.7 & 35.9 & 26.2 \\
Other/No Religion & 11.4 & 9.5 & 9.7
\end{tabular}

\section{Community level covariates}

Mean distance to the health center $(\mathrm{km})$

$\begin{array}{ccc}5.6 & 4.5 & 4.9 \\ 1,365 & \mathbf{2 , 2 2 0} & \mathbf{3 , 2 6 I}\end{array}$

\section{Infant and child morbidity}

The evaluation collected data on the symptoms associated with the three of the leading causes of death in early childhood namely diarrhea, cough accompanied by short, rapid breathing (for acute respiratory infections), and fever. Table 2 shows the prevalence of these symptoms in the intervention and control areas at baseline. The percentage of children under five years of age who were reported to have had diarrhea at any time in the two weeks preceding the interview was $20 \%$, with only a little difference between the control and the intervention areas. The 2010 Malawi DHS reports a similar figure of $17.5 \%$ nationally, nearly the same value in rural Malawi, and $16 \%$ in the Southern region where the study sites are located (NSO \& ICF Macro 20II). The prevalence of ARI symptoms was around $25 \%$, with a higher prevalence in the intervention communities. The prevalence of fever was $30.5 \%$ with no major difference across the two areas, and is comparable to figures from the 2010 DHS (NSO \& ICF Macro 20 I I).

Table 2. Prevalence of morbidity among children aged five years or younger, at baseline

Diarrhea in the preceding 2 weeks

Fever in the preceding 2 weeks

Cough accompanied by short, rapid breathing in the preceding 2 weeks

$\mathrm{N}$

\begin{tabular}{cccc}
\hline $\begin{array}{c}\text { Control } \\
\text { area }\end{array}$ & & $\begin{array}{c}\text { Interven- } \\
\text { tion area }\end{array}$ & Total \\
\cline { 1 - 1 } 21.5 & & 19.1 & 20.0
\end{tabular}

28.9

31.5

30.5

20.4

28.2

24.7

1,365

2,220

3,585
Unadjusted effects of the intervention on child health care use

Table 3 presents the simple DID estimates of the effect of CCPF on the outcomes of interest. There is a small, positive and statistically significant effect $(p<0.10)$ on exclusive breastfeeding until six months, resulting from a slight 
increase over time in the intervention area and seeming stagnation in the control area. The use of ORS to treat diarrhea dropped by about 1.9 percentage points in the intervention area and 3.7 percentage points in the control site. In total, there is no average treatment effect of CCPF on use of ORS among children who had diarrhea in the two weeks before the interview. At the other end of the scale, we note a negative ITT effect of the intervention on bednet use for children $(p<0.05)$, arising from a steeper increase over time in the control area (from $71 \%$ to $93 \%$ ) compared to the intervention area (increase from $82 \%$ to $95 \%$ ). The fact that mosquito net use at baseline was already high in the intervention area likely contributed to the negative effect. Overall, there is a negative and statistically significant unadjusted ITT effect of the project on the aggregate home-based care for children.

Table 3. Unadjusted difference in difference on the effects of the interventions on home-based and facility-based care for child health

$\begin{array}{lll}\text { Baseline Endline } & \text { Diff-in- } \\ \text { Diff }\end{array}$

\section{Home-based care for child health}

\begin{tabular}{|c|c|c|c|c|}
\hline Overall home-based care for child health & $\begin{array}{l}\text { Intervention } \\
\text { Control }\end{array}$ & $\begin{array}{l}0.098 \\
0.004\end{array}$ & $\begin{array}{l}0.254 \\
0.219\end{array}$ & $-0.059 * *$ \\
\hline $\begin{array}{l}\% \text { Children breastfed exclusively until } 6 \\
\text { months of age }\end{array}$ & $\begin{array}{l}\text { Intervention } \\
\text { Control }\end{array}$ & $\begin{array}{l}93.1 \% \\
94.5 \%\end{array}$ & $\begin{array}{l}94.1 \% \\
94.0 \%\end{array}$ & $0.014 *$ \\
\hline $\begin{array}{l}\% \text { Children who slept under a bed net } \\
\text { the previous night }\end{array}$ & $\begin{array}{l}\text { Intervention } \\
\text { Control }\end{array}$ & $\begin{array}{l}81.8 \% \\
70.6 \%\end{array}$ & $\begin{array}{l}95.2 \% \\
92.9 \%\end{array}$ & $-0.090 * *$ \\
\hline $\begin{array}{l}\% \text { Children who received oral } \\
\text { rehydration salts to treat diarrhoea }\end{array}$ & $\begin{array}{l}\text { Intervention } \\
\text { Control }\end{array}$ & $\begin{array}{l}74.7 \% \\
66.3 \%\end{array}$ & $\begin{array}{l}72.8 \% \\
62.6 \%\end{array}$ & 0.017 \\
\hline
\end{tabular}

\section{Facility-based care for child health}

\% Children with fever in last 2 weeks Intervention $\quad 67.5 \% \quad 52.1 \%$ $\begin{array}{llll}\text { who sought care from health facility } & \text { Control } & 59.1 \% & 62.7 \%\end{array}$

\begin{tabular}{cllll} 
& Control & $59.1 \%$ & $62.7 \%$ & \\
\hline $\begin{array}{c}\text { \% Children with symptoms of ARI in } \\
\text { last 2 weeks who sought care }\end{array}$ & Control & $67.6 \%$ & $70.8 \%$ & -0.030 \\
\hline $\begin{array}{c}\% \text { Children fully immunized by first } \\
\text { birthday }\end{array}$ & Intervention & $78.8 \%$ & $78.1 \%$ & \\
\cline { 2 - 5 } & Control & $77.7 \%$ & $75.8 \%$ & 0.013 \\
\hline
\end{tabular}

Statistical significance: ${ }^{*} \mathrm{p}<0.10,{ }^{* *} \mathrm{p}<0.05,{ }^{* * *} \mathrm{p}<0.01$ 
On Facility-based care, Table 3 shows a large, negative effect on facility care among children who had fever in the two weeks preceding the survey $(p<0.01)$. While facility care for fever increased over time in the control site (from 59\% to 63\%), it dropped nearly 15 percentage points in the intervention area (from $67 \%$ to $52 \%$ ). The proportion of children with symptoms of ARI in last 2 weeks who sought care at a facility, as well as the proportion of children fully immunized by the 12 months, remained largely unchanged in both the intervention and the control communities.
Adjusted effects of the intervention

Table 4 shows the effects of the intervention on individuals who actually used the services offered by CCPF. As can be seen, there is a large, positive effect of the treatment on the treated on the aggregate home-based care for child health $(p<0.01)$, arising solely from a sharp increase in mosquito net use among children whose mothers/caretakers used CCPF $(p<0.0 \mathrm{l})$. Indeed, there is no TOT effect on either breastfeeding until six months of age, or use of ORS among children who were sick with diarrhea in the two weeks preceding the interview.

Table 4. Adjusted effects of the intervention on home-based and facility-based care for children

\begin{tabular}{llll}
$\begin{array}{c}\text { ITT } \\
\text { effect }\end{array}$ & $\begin{array}{c}\text { TOT } \\
\text { effect }\end{array}$ & $N \quad$ Sub-sample \\
\cline { 4 - 4 } & & $N \quad$ Description
\end{tabular}

\section{Home-based care for child health}

Aggregate use of home-based care for child health

Child breastfed exclusively until six months of age

Under 5 child slept under a bed net last night

Under 5 child receiving oral rehydration salts to treat diarrhea

\begin{tabular}{|c|c|c|c|}
\hline$-0.07 \mid * *$ & $0.603 * * *$ & 3,585 & All children under five \\
\hline 0.011 & 0.006 & 3,585 & All children under five \\
\hline 094** & $0.568^{* * *}$ & 3,585 & All children under five \\
\hline 013 & -0.006 & 1,269 & $\begin{array}{l}\text { Children who had } \\
\text { diarrhea in last } 2 \\
\text { weeks }\end{array}$ \\
\hline
\end{tabular}

\section{Facility-based care for child health}

Child with fever in last 2 weeks who sought care from health facility

Child with symptoms of ARI in last 2 weeks who sought care

\begin{tabular}{|c|c|c|c|}
\hline$-0 .|8| * * *$ & $-0.499 * * *$ & 2,194 & $\begin{array}{l}\text { Children who had } \\
\text { fever in last } 2 \text { weeks }\end{array}$ \\
\hline-0.025 & -0.083 & I,895 & $\begin{array}{l}\text { Children who had ARI } \\
\text { in last } 2 \text { weeks }\end{array}$ \\
\hline 0.009 & 0.012 & 1,610 & $\begin{array}{l}\text { Children aged } 12-13 \\
\text { months }\end{array}$ \\
\hline
\end{tabular}

Child fully immunized by first birthday

Statistical significance: ${ }^{*} p<0.10,{ }^{*} p<0.05, * * * p<0.01$ 
The negative effect on facility-based care for fever treatment reported in the ITT model (in Table 3) is amplified in Table 4 , indicating a sharper negative impact of CCPF on facility-based care seeking for fever among children whose mothers/caretakers used the services offered by the intervention. This negative effect was not recorded on conditions that can only be addressed at the health facility, like immunization or the treatment of ARI.

\section{Insights from the qualitative data}

Qualitative data was gathered to add context and support to the quantitative findings of the evaluation. Overall, the most commonly mentioned theme to emerge from the qualitative data was the idea that the hotline helps to improve clients' knowledge of health problems and treatment methods, therefore enabling the user to make informed decisions about subsequent care-seeking behavior. One of the most prevalent arguments from the qualitative data in support of this point was that speaking with a CCPF community volunteer and utilizing the hotline allowed access to health information and situation-specific advice, which empowered caregivers to make informed decisions as well as to feel more knowledgeable when speaking to providers at a health facility. An example from a focus group discussion with women who used the services noted that:

"We first talk to Chipatala Cha Pa Foni worker before we decide to go to the health center...and if it is not a serious problem, he tells us what to do. But if the problem is serious, he advises us to take the child to the health center... and the clinical technicians would help the child if we tell him about the problem." [FGD with users]

The second most frequently mentioned reason for using CCPF was convenience, specifically in regard to seeking information from a community volunteer. This often meant avoiding unnecessary trips to the health facility for care that could be provided closer to home, through the pharmacy or community health workers. Similarly, as stock outs and shortages in trained staff are commonplace at many rural clinics, the hotline was often described as a means of informing the client about the availability of care at a particular health facility. This allowed them to either travel to the nearest clinic or avoid an unfruitful visit and instead seek medicine at a pharmacy or directly at the district hospital. A participant to a FGD with users told us:

"I was saying that an individual needs to first use Chipatala Cha Pa Foni in order to have prior information whether drugs will be available or not for what one is suffering from before going to the health centre. It seems that most drugs are not available and still we need to be discussing that before rushing to the health centre for it is better to first call Chipatala Cha Pa Foni workers to tell you what to do. By that they make sure that the disease that is to be treated has its drugs available." [FGD with users]

Another responded noted: "I am satisfied because the guidance I receive is the same as the one I get from the health center...We are satisfied because we receive similar guidance. On my part $I$ wanted those things because we were told 
there are some things we don't need to the health center to get treatment." [FGD with users]

Respondents also acknowledged that treatment that is available in the community and does not need to be administered by a health care worker, such as ORS, is timely and cost effective as it saves a trip to the facility. Respondents described being introduced to these home-based methods and talked through their administration in a compassionate manner.

[I called] several times. I called when I was pregnant then I started receiving tips and reminders from the time I was pregnant. I received a tip about my date of delivery until my child was born. After his birth I started receiving tips and reminders about how to take care of the child things like keeping the child warm... I really benefited from the tips and reminders and now my child is growing healthy." [IDI with female user]

\section{Discussion}

This study has contributed to addressing the evidence gap on the potential impact of mHealth on newborn and child health. It has harnessed the growing utility of mHealth to address supply and demand issues in order to improve the link between the facility and community. A positive effect of CCPF was observed on aggregate home-based care practices for child health, mainly due to bed net use to prevent malaria. Additionally, the use of CCPF services contributed to the reduction in the burden of care-seeking for childhood illness at health facilities in the study area that could be treated at home, primarily driven by a substantial reduction in visits for fever.

As a result of the low uptake of services offered by the intervention, the ITT estimates are not likely to provide a good indication of the impact of the intervention. Unlike the ITT approach, the TOT method attempts to adjust for a critical self-selection bias: there are individuals in the control area who would not be able or willing to use the services even if they were offered. A mere comparison of the control and intervention areas as in the ITT principle, without accounting for this selection would lead to biased impact estimates (Angrist et al. 1996).

Although the use of mHealth for $\mathrm{MNCH}$ is becoming increasingly popular, services like CCPF that promote twoway communication between caregivers and professional health resources as a means to promoting home-based care and lessening unnecessary burden on the health system are not yet widespread (mHealth Alliance 20I2). One such application of mHealth, Wired Mothers, has been implemented in Tanzania with aims of strengthening communication between caretakers and primary health care units and has shown positive impact on maternal health outcomes (mHealth Alliance 20I2). More projects have used voice or text message reminders for awareness and knowledge building around antenatal, delivery and postnatal care (mHealth Alliance 20I2). Our finding on increased home-based care lends support to the evidence treatment of minor levels of childhood illnesses is possible at the community level (WHO \& UNICEF 20I2).

One of the objectives of CCPF was to ensure that seeking facility care was purposeful and necessary so as to reduce facility burden and increase 
resources for the severe cases. The results of this analysis show that CCPF improved home-based care for fever, and as a result, demonstrated that a tollfree hotline and messaging service could reduce the workload of facility staff for conditions that can be treated at home. In-depth interviews reinforced this result in that caretakers appreciated the CCPF services for two reasons: I) the services helped them to avoid unnecessary trips to health facilities, and 2) if referrals were required, then information was provided on where to best access care. The combination of convenience and knowledge on home-based care, as highlighted by respondents, culminates in the empowerment of users to treat illness in a timely manner within their own homes or to seek and receive quality care at an appropriate facility.

mHealth, and the CCPF application specifically, should be utilized as an opportunity to address current gaps in the health system, particularly with respect to health workforce barriers, in efforts to improve newborn and child health outcomes. Care-seeking is a key element in improving health and survival, particularly of newborns, and must be supported through the strengthening of supply and demand side inputs. It relies on the availability of and accessibility to services at the point of care, and on community awareness and demand including prompt recognition of danger signs and timely decision-making and action to seek care (Herbert et al. 2012, Black et al. 2010). CCPF makes a major contribution in this process by effectively managing the immediate steps that follow recognition of danger signs through either an immediate solution in the community or guidance and encouragement on facility care.
No significant impact was observed on the administration of ORS for diarrhea, care-seeking for ARI and uptake of immunizations in the first year. In Malawi, only $70 \%$ and $30 \%$ of children suffering from pneumonia were taken to a health provider or treated with antibiotics respectively. Meanwhile, only $69 \%$ of children with diarrhea were treated with ORS and only 62\% received advanced care (NSO and ICF Macro 20II). CHWs are reported to have the strongest impact on case management of pneumonia (Bahl et al. 2010). Additionally, Malawi's national iCCM strategy has been shown to effectively treat ARIs (Fullerton et al. 20II). Integration of mHealth and community health workers could improve care-seeking around diarrhea and ARls. According to a comprehensive analysis of the current state of mHealth in Malawi conducted by GSMA (GSMA 2014), various organizations have implemented the use of SMS reminders for immunizations in the country. Partnerships and lessons learned from these programs could enhance timely immunization using the CCPF model.

A limitation of our analysis is that home-based care for fever was not captured in the data. As a consequence, the marked drop in facility-based care for fever could not be contrasted with trends in home-based care for fever. Likewise, the absence in our data of facility-based care for diarrhea limits our ability to fully understand the effect of the intervention on health care seeking behaviors. With the control district neighboring the intervention site, there may be a potential contamination effect. The endline data shows that less than $3 \%$ of individuals in the control 
communities were aware of the services offered by the intervention, suggesting that contamination may not have occurred.

\section{Conclusion and Programmatic Implications}

CCPF provides an invaluable opportunity and insights for implementers and policymakers on mHealth and community-based programming to improve the quality of newborn and child health care delivery. CCPF has demonstrated that mHealth can work to improve newborn and child health even in low resource settings. If efforts are made to scale-up CCPF within Malawi's health systems context, in light of the Ministry of Health's commitment to newborn and child health, there is major potential for reductions in newborn and child morbidity and mortality and acceleration towards the achievement of relevant MDGs.

As Malawi is in the process of implementing iCCM at scale and integrating it into existing programming (Fullerton et al. 20II), our findings suggest an opportunity to test and scaleup complementary approaches to improve newborn and child health. The mHealth Alliance emphasizes the value of implementing interventions that merge mHealth with existing health system resources and initiatives to tackle newborn and child health, in order to accelerate demand and expand and strengthen the capacity and spectrum of human resources (mHealth Alliance 2012).

In order to enhance the use of CCPF and its impact on home-based care in settings with low penetration of cellphones, mobile phone access needs to be expanded through the distribution of more community volunteers with functioning, reliable mobile phones in the intervention area. Advocacy is another mechanism for increasing awareness of CCPF, which can be done through community mobilization as well as promotion of the services at the facility during delivery, routine antenatal, and postnatal care visits. Data is also needed on cost and cost-effectiveness of this model to further research on this model's potential application in different settings within and outside of Malawi. Finally, the scale-up of CCPF needs to be designed and implemented within the context of the existing health system and current service delivery initiatives (mHealth Alliance 2012) in an effort to harness the benefits of CCPF to overcome major constraints to the delivery of care and shortages in human resource capacity (Travis et al. 2004, de Sousa et al. 2012).

\section{Acknowledgements}

The CCPF project is part of Innovations for Maternal, Newborn \& Child Health, an initiative of Concern Worldwide U.S. funded through a multiyear grant from the Bill \& Melinda Gates Foundation. The Government of Norway and the United Nations Foundation also supported the Malawi mHealth project (CCPF) through the Innovation Working Group Catalytic mHealth Grants program as part of the UN Secretary General's Every Women Every Child strategy. CCPF was implemented by VillageReach, an international NGO headquartered in Seattle, USA. We would like to give special thanks to the Reproductive Health Unit and its Director, Mrs. Fannie Kachale, and the Balaka District Health 
Office for their support of CCPF. The evaluation was conducted by Invest in Knowledge Initiative (IKI), a Malawibased research institution, with the leadership of Professor Susan Watkins of University of Pennsylvania and Dr. Amanda Robinson of Ohio State University. The authors would like to thank Dr. Amanda Robinson for her contribution to data analysis. They are grateful to Ms. Jessica Crawford of VillageReach, Malawi for her comments on the manuscripts, and Ms. Justine Dowden of Columbia University for her contribution to the coding of the qualitative data. They acknowledge the insightful comments from the anonymous reviewers.

\section{Authors' Contributions}

JCF \& LB designed the study; LB led the qualitative analyses; JCF led the quantitative analyses; JCF, LB, LV and ZJ all contributed to the writing of the manuscript. All authors discussed the results and commented on the manuscript at all stages.

\section{References}

ACCESS. 2005. "Household-To-Hospital Continuum of Maternal and Newborn Care." USAID, 2005

Angrist, J.D., Imbens, G.W., and Rubin, D.B. 1996. "Identification of causal effects using instrumental variables." Journal of the American Statistical Association 91 (434):444-455.

Bahl, R., Qazi, S., Darmstadt, G.L., and Martines, J. 2010. "Why is continuum of care from home to health facilities essential to improve perinatal survival?" Seminars in Perinatology 34(6): 477-485.

Bhutta, Z.A., Das, J.K., Bahl, R. et al. 2014. "Can available interventions end preventable deaths in mothers, newborn babies, and stillbirths, and at what cost?" Lancet 384: 347-370.

Black, R.E., Cousens, S., Johnson, H.L. et al. 2010. "Global, regional, and national causes of child mortality in 2008: a systematic analysis." Lancet 375: 1969-87.

Black, R.E., Morris, S.S., and Bryce, J. 2003. "Where and why are 10 million children dying every year? " Lancet 36I: 2226-34

Braun, V., and Clarke, V. (2006). "Using thematic analysis in psychology." Qualitative Research in Psychology 3(2): 77-10I.

CORE Group. 2009. Community Approaches to Child Health in Malawi-Applying the C-IMCl Framework.

Costello, A., Osrin, D., and Manandhar, D. 2004. "Reducing maternal and neonatal mortality in the poorest communities." BMJ 329: I I 66.

Crawford, J., Larsen-Cooper, E., Jezman, Z., Cunningham, S.C., and Bancroft, E. "SMS versus voice messaging to deliver $\mathrm{MNCH}$ communication in rural Malawi: assessment of delivery success and user experience." Global Health: Science and Practice. January 2014.

Darmstadt, G.L., Kinney, M.V., Chopra, M. et al. 2014. "Who has been caring for the baby?" Lancet 384: 174-188.

de Sousa, A., Tiedje, K.E., Recht, J., Bjelic, I., and Hamer, D.H. 2012. "Community case management of childhood illnesses: policy and implementation in Countdown to 2015 countries." Bull World Health Organ 90:183-190.

Fotso, J.C., Robinson, A.L., Noordam, A.C. and Crawford, J. 2015. "Fostering the use of quasi- 
experimental designs for evaluating public health interventions: Insights from an mHealth project in Malawi”.African Population Studies 29(I): 1607-1627.

Free, C., Phillips, G., Watson, L., Galli, L., Felix, L., et al. 2013. "The Effectiveness of Mobile-Health Technologies to Improve Health Care Service Delivery Processes: A Systematic Review and MetaAnalysis.” PLoS Med I0(I):el00I363.

Fullerton, J.T., Schneider, R.M., and Auruku, A. 201I. "USAID/Malawi Community Case Management Evaluation.” USAID, 20I I.

GSMA Mobile for Development. 2014. "mHealth country feasibility report" Malawi. 2014.

Herbert, H.K., Lee, A.C.C., Chandran, A., Rudan, I., and Baqui, A.H. 2012. "Care seeking for neonatal illness in low- and middle-income countries: A systematic review." PLoS Med 9(3): el00II83.

Invest in Knowledge (IKI). 20I3. "Evaluation of The Information and Communications Technology to Improve Health Services for Mothers and Children Project." Malawi, 20I3.

Kadzandira, J.M. and Chilowa, W.R. 2001. "The role of Health Surveillance Assistants (HSAs) in the Delivery of Health Services and Immunization Malawi." University of Malawi, Centre for Social Research; 2001.

Kling, J.R., Leibman, J.B. and Lawrence, K.F. 2007. "Experimental analysis of neighborhood effects." Econometrica 75(I):83- II9.

Kok, M.C. and Muula, A.S. 2013. "Motivation and job satisfaction of Health Surveillance Assistants in Mwanza, Malawi: an explorative study." Malawi Medical Journal 25(I): 5-II.

Labrique, A. 2010. "Maternal and neonatal health: opportunities and challenges for mHealth in resourcelimited settings." Johns Hopkins Bloomberg School of Public Health, Baltimore, Maryland (USA). 2010.

Mane, A.B., Dohare, S., and Gitte, S.V. 2012. "Child Health: Understanding the home care practices in some illnesses among under five children in IMNCl implemented rural area." Int J Biol Med Res 3(5): I 25 I-I 254

mHealth Alliance. 2012. "Leveraging Mobile Technologies to Promote Maternal \& Newborn Health: The Current Landscape \& Opportunities for Advancement in Low-Resource Settings." mHealth Alliance. 2012.

Namakhoma, I., Banda, H., and Rodríguez, D.C. 2013. "A Policy Analysis of Community Case Management of Childhood Illnesses in Malawi. REACH Trust for Johns Hopkins Bloomberg School of Public Health, 2013."

NSO (National Statistical Office) and ICF Macro. 20II. "Malawi Demographic and Health Survey 2010." Zomba, Malawi, and Calverton, Maryland, USA: NSO and ICF Macro

Perry, H.B., Zulliger, R., and Rogers, M.M. 20I4. "Community health workers in low-, middle-, and highincome countries: An overview of their history, recent evolution, and current effectiveness." Annual Review of Public Health 35: 399-42I.

Travis, P., Bennett, S., Haines, A., Pang, T., Bhutta, Z., Hyder, A.A. et al. 2004. "Overcoming health-systems constraints to achieve the Millennium Development Goals. " Lancet 364:900-906. 
UN (United Nations). 2013. "The WHO \& TDR, 20I3. WHO Informal Millennium Development Goals Consultation on Fever Management Report 2013." United Nations, New in Peripheral Health Care Settings: A York, 2013.

UNICEF. 2013. "Committing to Child Survival: A Promise Renewed Progress Report 2013." UNICEF, New York, 2013. Global Review of Evidence and Practice. WHO, Geneva, 2013.

Wang, H., Liddell, C.A., and Coates, M.M. 20I4. "Global, regional, and national levels of neonatal, infant, and WHO \& UNICEF. 2012. "WHO/UNICEF JOINT STATEMENT on Integrated Community Case Management (iCCM): An Equity-Focused Strategy to Improve Access to Essential Treatment Services for Children." WHO, UNICEF, 2012. under-5 mortality during 1990-2013: a systematic analysis for the Global Burden of Disease Study 2013". Lancet, Published Online May 2014.

Zimba, E., Kinney, M.V., Kachale, F. et al. 2012. "Newborn survival in Malawi: a decade of change and future implications." Health Policy Planning 27: 88-103. 